\title{
Understanding foraging flexibility in urban vervet monkeys, Chlorocebus pygerythrus, for the benefit of human-wildlife coexistence
}

\author{
Harriet R. Thatcher ${ }^{1,2,3}$ (D) Colleen T. Downs ${ }^{2}$ (D) - Nicola F. Koyama ${ }^{1}$ (D) \\ Published online: 24 May 2020 \\ (C) The Author(s) 2020
}

\begin{abstract}
Generalist wildlife species often thrive in urban environments because of increased anthropogenic resources. However, humanwildlife interactions, especially if negative, raise concerns for urban wildlife management. An enhanced understanding of wildlife behavioural flexibility has been suggested to be a key tool to provide educated and effective management strategies. We therefore investigated how availability of semi-naturally occurring food affected behavioural foraging patterns of urban vervet monkeys (Chlorocebus pygerythrus), a generalist primate commonly found in urban areas of KwaZulu-Natal, South Africa. Over one year, we conducted $20 \mathrm{~min}$. focal animal observations recording foraging behaviour and food consumption. We used a combination of a generalised linear model and descriptive statistics to examine the relationship between anthropogenic food consumption and semi-natural food availability. Our analyses showed that anthropogenic food consumption decreased as semi-natural food availability increased. We also showed that increased aggression from humans towards vervet monkeys decreased time spent foraging on anthropogenic food. Our study highlights how vervet monkeys have adapted to their urban landscape, showing foraging flexibility in response to available food resources and the frequency of human interactions. We suggest how our results can be applied for management recommendations, particularly controlling anthropogenic food availability and decreasing negative human-wildlife interactions.
\end{abstract}

Keywords Ethnoprimatology $\cdot$ Wildlife management $\cdot$ Human-wildlife interactions $\cdot$ Urban landscape

\section{Introduction}

Due to increasing human populations, almost all wildlife today live in habitats that are altered to some degree by anthropogenic activities (Tilman et al. 2017). Generalist wildlife

Harriet R. Thatcher

harriet.thatcher@ed.ac.uk

Colleen T. Downs

downs@ukzn.ac.za

Nicola F. Koyama

n.f.koyama@1jmu.ac.uk

1 School of Biological and Environmental Sciences, Liverpool John Moores University, Liverpool, UK

2 Centre for Functional Biodiversity, School of Life Sciences, University of KwaZulu-Natal, P/Bag X01, Scottsville, Pietermaritzburg 3209, KwaZulu-Natal, South Africa

3 Department of Biomedical Sciences, University of Edinburgh, Edinburgh, UK species often exploit urban environments because of increased anthropogenic resources (Lowry et al. 2013). Consequently the urban landscape is of particular concern for wildlife management because of increased wildlife abundance and humanwildlife interactions (McKinney 2002; Baker and Harris 2007). Understanding how an animal persists in an anthropogenically disturbed environment is imperative to provide guidance for human-wildlife cohabitation and reduce negative interactions (Dickman 2010; Nowak and Lee 2013; Hockings et al. 2015; Patterson et al. 2019).

An increase in wildlife inhabiting the anthropogenic dominated landscape is creating a complex scale of interactions for both humans and wildlife (Nyhus, 2016). Urban areas often provide concentrated high value resources to wildlife that generalist species can exploit (Widdows and Downs 2016). However, human-wildlife cohabitation can have potential costs for wildlife such as increased aggression from humans (Nyhus 2016), that may impose time constraints or elicit a stress response (Kaburu et al. 2019a). The multiple facets of human-wildlife interactions need to be considered to understand wildlife behavioural flexibility for the benefit of human- 
wildlife coexistence (Thatcher et al. 2019a, b). Behavioural ecology has been highlighted as a key tool to understand an animal's response to anthropogenic pressures (Jokimäki et al. 2011). An enhanced understanding of wildlife behavioural responses to the human-wildlife interface can facilitate more informed management strategies at an environmental level (Sol et al. 2002; McLennan et al. 2017) and benefit ecosystem health (Bradley and Altizer 2007; Becker and Hall 2014).

Foraging flexibility is commonly acknowledged as a key attribute for the survival and success of urban species (Lowry et al. 2013; Widdows and Downs 2018). Various studies have highlighted that anthropogenic food is a key driver behind the nature of human-wildlife cohabitation e.g. large spotted genets, Genetta tigrina (Widdows and Downs 2015) and woolly-necked storks, Ciconia microscelis (Thabethe and Downs 2018). Anthropogenic food resources provide a more reliable foraging option for urban wildlife as they are less likely to be affected by seasonal fluctuations (Bateman and Fleming 2012; Lowry et al. 2013). A better understanding of wildlife's dependence on anthropogenic food sources and potential to sustain on available vegetation in the urban matrix is necessary (Stofberg et al. 2019).

Currently, studies distinguish between natural foods, that are wild food items grown naturally without human intervention, and anthropogenic food resources, such as dumps, bird feeders and crops that are produced or grown by people (Freitas et al. 2008; Hockings et al. 2009; Oro et al. 2013; Cancelliere et al. 2018; Kaburu et al. 2019b; Marty et al. 2019a, b). In comparison, the urban landscape is a complex matrix providing a variety of food sources from human provisioned food and waste, to productive and well-maintained gardens and open spaces (McKinney 2002). Considering the variation in anthropogenic pressures and resources, current terminology used for wildlife living in the anthropogenic landscape is not transferable to urban wildlife populations. The term anthropogenic food resources implies that the resource is a food item for humans which has implications in terms of human-wildlife conflict. Crops are likely to be a much more valuable and controlled resource than for example, leisure areas of planted habitat that have little worth as human food. Thus, here we consider horticultural plants as "semi-natural food", developing on other urban literature that considers the value of a maintained ecosystem (Pautasso et al. 2011; Trueman 2017).

Due to their intelligence and sociality, primates pose a complex challenge to execute effective management plans (Woodroffe et al. 2005; Strum 2010). Research on primates living in anthropogenically modified habitats has shown a degree of preference for anthropogenic features, particularly a behavioural preference for increased anthropogenic food resources (Saj et al. 1999; Hoffman and O'Riain 2012; Sha and Hanya 2013; Bryson-Morrison et al. 2016; BrysonMorrison et al. 2017; Thatcher et al. 2019b). The association between crop availability and natural resources has been considered in primates, which show a preference for high calorie resources (Hockings et al. 2009; Sha and Hanya 2013; Chaves and Bicca-Marques 2016; McLennan and Ganzhorn 2017; Cancelliere et al. 2018). However, the relationship in the urban landscape between available natural resources and anthropogenic food resources for primates has not been explored.

Cercopithecoids are the most successful extant primates to adapt to human-cohabitation (Lambert 2005). Cercopithecines are unique in that they possess cheek pouches, likely an adaptive feature that is highly beneficial in the urban landscape (Lambert 2005; Humle and Hill 2016). Vervet monkeys (Chlorocebus pygerythrus) are a cercopithecoid commonly found throughout the urban matrix of KwaZulu-Natal (Thatcher et al. 2018) and have been shown to have a complex relationship with humans, raising concerns for wildlife management (Patterson et al. 2017). Furthermore, previous research has suggested that urban vervet monkeys display foraging flexibility in the urban landscape (Thatcher et al. 2019b). Vervet monkeys therefore present a suitable species to increase our knowledge of foraging flexibility for the benefit of human wildlife management.

Understanding species dietary selection and foraging flexibility is important for human wildlife cohabitation (Litvaitis 2000). Therefore, the primary objective of this study was to increase our understanding of how semi-natural food availability influenced vervet monkey's consumption of humanderived food and how this may have implications for human-wildlife management plans. We predicted that consumption of human food would increase when semi-natural food availability was low; however, we still expected there to be a high dependency on anthropogenic food because of its generally high calorific value (Cancelliere et al. 2018). Based on recent studies that highlight the importance of considering multiple dimensions of human-wildlife cohabitation (Thatcher et al. 2019a, b), we predicted that human-monkey aggression would impose time constraints and decrease foraging (Kaburu et al. 2019a, b; Marty et al. 2019a; Thatcher et al. 2019b).

\section{Methods}

\section{Study population}

We conducted our study at Simbithi eco-estate, a $4.7 \mathrm{~km}^{2}$ private gated housing development in Durban north coast, KwaZulu-Natal, South Africa $\left(29.5140^{\circ} \mathrm{S}, 31.2197^{\circ} \mathrm{E}\right)$. The estate is comprised of a variety of accommodation options including apartment blocks, retirement complexes and general housing within an urban mosaic. The estate has other anthropogenic leisure developments including restaurants and leisure facilities. The estate encourages wildlife research to help 
biodiversity management plans (Thatcher et al. 2018, 2019a, b; Patterson et al. 2019). Residents had mixed responses to vervet monkey presence ranging from actively encouraging vervet proximity to humans (intentional feeding by humans) to actively deterring vervet monkeys from human property (human aggression).

The estate had seven known groups of vervet monkeys (Simbithi eco-estate, 2017, pers. comm.), although this study focused on the five groups that regularly stayed within the borders of the estate. Group size varied from 14 to 42 individuals (Ballito (14): 3 males, 6 females, 5 juveniles; Farmyard (23): 4 males, 10 females, 9 juveniles; Savannah (25): 4 males, 10 female, 11 juveniles; Goodies (29): 5 males, 10 females, 14 juveniles; Herron (42): 5 males, 14 females, 23 juveniles) (Thatcher 2019). Vervet monkeys were well habituated to humans because of their regular proximity to human residences and infrastructure. All adult vervet monkeys were identifiable via distinguishable markings; therefore, all 71 adult vervet monkeys were observed for this study.

\section{Data collection}

We collected data from March 2016 - February 2017, covering the four calendar seasons (summer: November-March, autumn: April-June, winter: July-August, spring: SeptemberOctober) (SANBI 2017).

We used focal animal sampling techniques to observe each individual for $20 \mathrm{~min}$ (Altmann 1974), noting all events when a monkey was seen foraging (including moving objects/ searching for food before feeding) and feeding (manipulating/picking and actually eating items) (Ménard et al. 2013). We recorded food category as either "semi-natural food" or "anthropogenic food". Semi-natural food was any naturally occurring and/or managed vegetation, with food types in this category recorded as: "fruit", "grass", "leaves", "flowers" and "other natural food" (vegetation that could not be identified or did not fit in the aforementioned categories) as well as "invertebrates". We categorised human-derived resources as anthropogenic food, with food types including: "provisioned food" (food directly fed to monkeys from humans), "opportunistic feeding" (anthropogenic food obtained opportunistically from leisure facilities or waste) and "other anthropogenic-derived food" (any occasion when a monkey was seen consuming anthropogenic food, yet the researcher had not observed them obtain the food so the origin was unknown, although it should be acknowledged this could have happened prior to the behavioural observation).

We conducted observations from dawn until dusk (up to $8 \mathrm{~h}$ in winter and $16 \mathrm{~h}$ in summer) for a minimum of three weeks per month. Where possible we conducted a minimum of one observation per monkey per month, spread throughout the day. In total 3774 focal animal observations were conducted across all groups.
As well as anthropogenic food consumption, we used all occurrence sampling to record all negative interactions between humans and vervet monkeys during dawn to dusk daily follows. Negative human incidents included any form of aggression from humans towards vervet monkeys. We considered a negative event to be over once all parties had retreated out of visual contact of each other and we recorded a new event when there had been no incident in the preceding 20 $\mathrm{min}$. We calculated a rate (frequency/hour) of negative human incidents per group each month.

We calculated an estimate of natural food availability, following practiced phenology protocol. We conducted five randomly placed walking transects within each groups' home range noting all specimens $\geqq 10 \mathrm{~cm}$ diameter at breast height (Chapman et al. 2005; Marshall and Wich 2013). We retrospectively identified windows of fruit and flower availability using horticultural records for the region (Boon 2010). As in some previous studies (Blake 1990; Wirminghaus et al. 2001), we ranked species according to stage of development using these same records $(0=$ no fruit, $1=$ setting, $2=$ unripe, $3=$ ripe, $4=$ moribund). We added the development value of all plants per transect, combining the five transects per group to create a monthly semi-natural food estimate per group per month.

\section{Data analyses}

We used descriptive statistics to show an overview of vervet monkey diets, considering both specific food type and food category. We calculated diet composition as a percentage frequency by taking the number of times food (type/category) was consumed during focal observations divided by the total number of focal behavioural observations, multiplied by 100 .

For behavioural data we converted the duration of foraging per focal observation to percentage of time spent foraging per focal observation and combined focal observation percentages to create a monthly average per group. We conducted all analyses using R statistical software version 3.3.2 (R Project 2013) with the significance level set at $\mathrm{P}<0.05$. Behavioural data were found to be not normally distributed by inspecting Q-Q plots and using the Shapiro-Wilk's test $(p \leq 0.001)$ (Ghasemi and Zahediasl 2012). As data were non-normal we ran a generalised linear mixed model with a Gamma distribution using the lme4 package (Bates 2010). We set percentage of time foraging on anthropogenic food (per group, per month) as the dependent variable $(N=60)$. We created an a priori maximum model that included monthly semi-natural food availability, mean monthly negative human incidents (per hour), mean monthly group size and season as fixed effects. We included group identity as a random effect. We calculated the variation inflation index of each predictor for inclusion in our model using the car package (Fox et al. 2007), setting the inclusion level at $<3$ (Zuur et al. 2010). We further 
bootstrapped our confidence intervals to test if each factor in our model was significant; if the upper and lower confidence intervals straddled 0 then we did not consider the variable significant (Wood 2005). To check the assumptions of our model were not violated we assessed the fit of each model by graphically checking residuals for normality and using the 'acf' function to test for correlation in the residuals.

\section{Ethical note}

This study was purely observational. We adhered to the legal requirements of South Africa for the ethical treatment of primates under Liverpool John Moores University ethical permit number NK_HT/2017-6.

\section{Results}

When considering specific food types, 'fruit' (30.2 $\pm 33.49 \%)$ and 'other anthropogenic-derived food' $(23.3 \pm 23.21 \%)$ were the two most commonly consumed food types (Table 1). The greatest percentage of time was spent consuming 'other anthropogenic-derived food' ( $44.9 \pm 16.15)$, followed by the other two anthropogenic food types, 'provisioned' (43.8 \pm $13.53)$ and 'opportunistic feeding' (42.6 \pm 16.30$)$ (Table 1).

On average vervet monkeys spent a greater percentage of time per focal observation foraging on anthropogenic food $(44.1 \pm 15.93 \%)$ and less time per focal observation foraging on semi-natural food (15.6 $\pm 15.71 \%)$ (Table 2). However, vervet monkey's consumed more natural food $(61.1 \pm 8.94)$ in their diet than anthropogenic food (38.6 \pm 8.66$)$ (Table 2.) Although these results seem contradictory, this is due to the difference in measurements. Time spent foraging is measured as the percentage of focal observation foraging (\% duration), whereas diet composition was measured as the number of times a food was consumed per focal observation (\% frequency). Therefore these results suggest that vervet monkeys spend more time foraging on anthropogenic food, but anthropogenic food is consumed less frequently. Additionally, our descriptive data showed that the consumption of anthropogenic food decreased as semi-natural food availability increased in the spring and summer (Fig. 1).

We found that the percentage of time spent foraging was significantly decreased by increasing semi-natural food availability (Table 3; Fig. 2a) and negative human incidents (Table 3; Fig. 2b).

Additionally, our results also showed a seasonal effect, significantly less time was spent foraging on anthropogenic food in the summer than winter and autumn (Table 3 ).

\section{Discussion}

Overall our findings showed a relationship between food resources (anthropogenic and semi-natural) and the foraging behaviour of urban vervet monkeys. Our data showed that vervet monkeys exhibit foraging flexibility in response to available food resources.

Our descriptive data showed that vervet monkeys spent a greater percentage of time foraging on anthropogenic food. Previous research has highlighted that urban primates spend less time foraging when they have access to anthropogenic food (Saj et al. 1999; Jaman and Huffman 2013). However, these studies are not comparable with our results as the category and definition of natural food are not representative of an
Table 1 Mean monthly foraging patterns showing the breakdown of food category (anthropogenic/semi-natural) into specific food types. Data shows the mean diet composition $(\% \pm \mathrm{SD})$ and the percentage of focal observation spent foraging on food type $(\% \pm \mathrm{SD})$ for five study troops of urban vervet monkeys, Simbithi eco-estate, KwaZulu-Natal, South
Africa. Diet composition was calculated as a percentage frequency of food type eaten per observation (frequency of food type eaten / total no. obs) x 100 and time spent foraging calculated as a percentage (duration of foraging per obs. / duration of obs.) x 100

\begin{tabular}{llll}
\hline Food category & Food type & Diet composition (\% frequency) & Time spent foraging per obs. (\% duration) \\
\hline Anthropogenic food & Other anthropogenic-derived food & $23.3( \pm 23.21)$ & $44.9( \pm 16.15)$ \\
& Opportunistic feeding & $11.1 \pm 10.46)$ & $42.6( \pm 16.30)$ \\
& Provisioned food & $4.2( \pm 2.87)$ & $43.8( \pm 13.53)$ \\
Semi-natural food & Fruit & $30.2 \pm 33.49)$ & $16.2( \pm 17.66)$ \\
& Grass & $20.2 \pm 21.71)$ & $16.0( \pm 14.47)$ \\
& Leaves & $5.6( \pm 6.43)$ & $12.8( \pm 10.43)$ \\
& Flower & $2.6( \pm 0.09)$ & $8.8( \pm 5.70)$ \\
& Other semi-natural food & $2.2( \pm 0.87)$ & $25.6( \pm 14.77)$ \\
& Invertebrates & $0.6( \pm 0.03)$ & $2.0( \pm 1.51)$ \\
\hline
\end{tabular}


Table 2 Mean monthly foraging patterns per group, showing both the diet composition of the respective food category (anthropogenic and semi-natural) $(\% \pm \mathrm{SD})$ and the percentage of focal observation spent foraging on food $(\% \pm \mathrm{SD})$ across five study groups of urban vervet monkeys, Simbithi eco-estate, KwaZulu-Natal, South Africa. Diet composition was calculated as a percentage frequency of food category eaten per observation (frequency of food category eaten / total no. obs) $\mathrm{x}$ 100 and time spent foraging calculated as a percentage (duration of foraging per obs. / duration of obs.) x 100

\begin{tabular}{|c|c|c|c|c|c|}
\hline \multirow[b]{2}{*}{ Group } & \multirow[b]{2}{*}{ Group size } & \multicolumn{2}{|c|}{ Anthropogenic food } & \multicolumn{2}{|l|}{ Semi-natural food } \\
\hline & & $\begin{array}{l}\text { Diet composition } \\
\text { (\% frequency) }\end{array}$ & $\begin{array}{l}\text { Time spent foraging per obs. } \\
\text { (\% duration) }\end{array}$ & $\begin{array}{l}\text { Diet composition } \\
\text { (\% frequency) }\end{array}$ & $\begin{array}{l}\text { Time spent foraging per obs. } \\
\text { (\% duration) }\end{array}$ \\
\hline Ballito & $14( \pm 1.17)$ & $43.9( \pm 4.18)$ & $42.7( \pm 13.49)$ & $56.1( \pm 7.49)$ & $11.9( \pm 13.98)$ \\
\hline Farmyard & $23( \pm 0.25)$ & $32.4( \pm 5.03)$ & $44.5( \pm 14.13)$ & $67.6( \pm 6.63)$ & $21.3( \pm 19.83)$ \\
\hline Savannah & $25( \pm 0.44)$ & $38.2( \pm 5.24$ & $41.9( \pm 16.71$ & $61.8( \pm 8.77)$ & $18.4( \pm 16.19)$ \\
\hline Goodies & $29( \pm 1.32)$ & $35.2( \pm 2.17)$ & $46.7( \pm 19.41)$ & $64.8( \pm 6.98)$ & $13.2( \pm 13.84)$ \\
\hline Herron & $42( \pm 1.03)$ & $42.8( \pm 7.93)$ & $44.8( \pm 15.80)$ & $57.2( \pm 9.51)$ & $12.1( \pm 11.62)$ \\
\hline Mean & & $38.6( \pm 8.66)$ & $44.1( \pm 15.93)$ & $61.1( \pm 8.94)$ & $15.6( \pm 15.71)$ \\
\hline
\end{tabular}

urban dwelling primate. To our knowledge we present the first analysis on urban primates whose available food sources are cultivated by humans (both semi-natural aesthetic plants and anthropogenic food sources). We suggest that time foraging on anthropogenic food increased because this human derived food is generally a limited high value resource and therefore monkeys may spend more time foraging on anthropogenic food to benefit from this unpredictable high calorie resource.

Additionally, our descriptive data showed that 'fruit' and 'other anthropogenic food' were the most commonly consumed food items, likely because of the high calorie count. When considering anthropogenic food, 'other' covered anthropogenic foraging events where the source was not seen by the observer; therefore it is likely that this could have included food from bins, leisure facilities or provisioning, thus showing vervet monkeys opportunistic foraging techniques. Direct provisioning and interactions with humans can have potentially negative consequences for animals such as disease transmission and habituation (Soulsbury and White 2015), exacerbating the negative relationship associated with human-wildlife cohabitation. Therefore, management should make efforts to discourage provisioning within the estate and provide guidance to residents on preventative measures for opportunistic feeding such as reducing access by either shutting windows and doors or using bars/nets to keep vervet monkeys out of their property and reducing attraction by

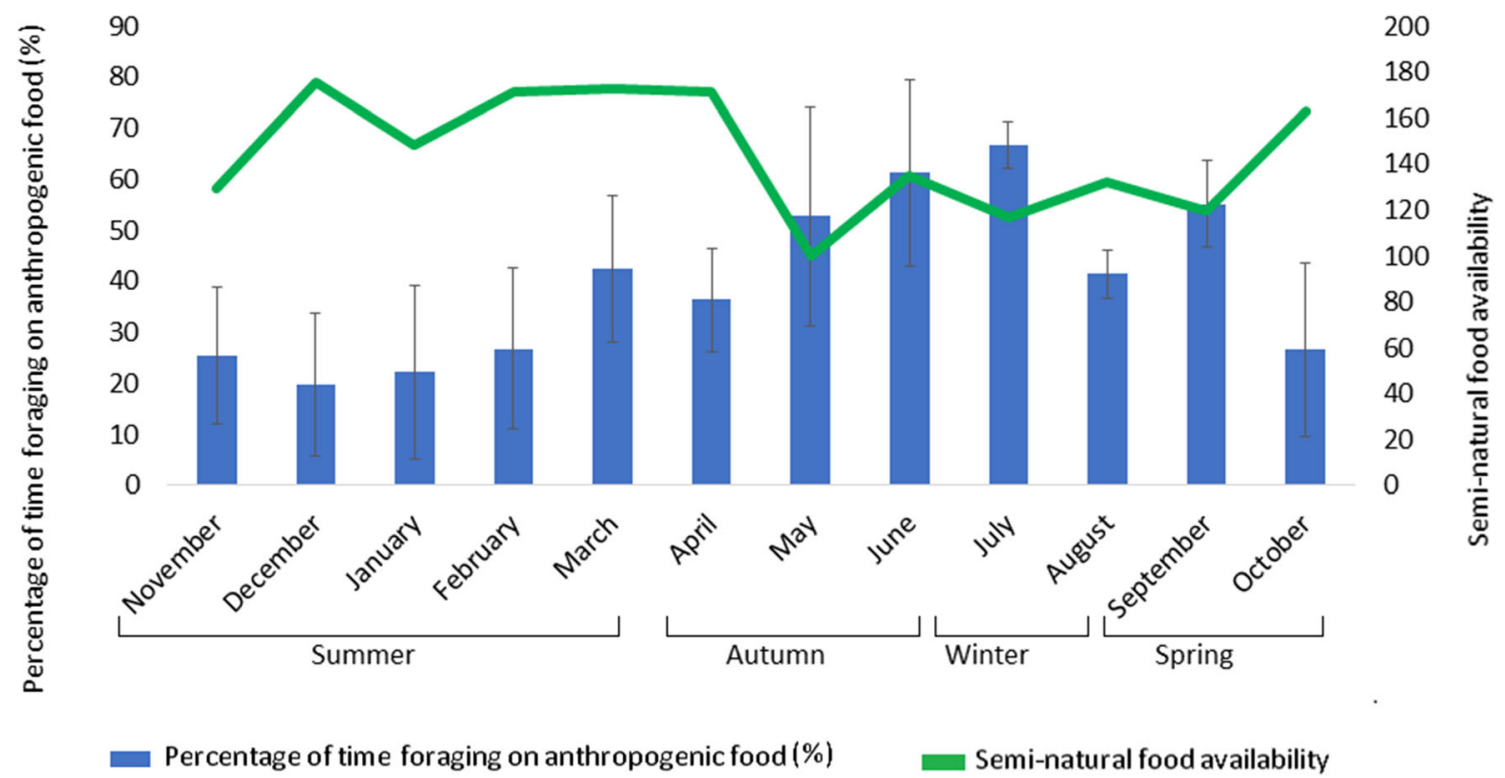

Fig. 1 Mean monthly percentage (\%) of time spent foraging on anthropogenic food (blue) ( \pm SD), where the thick green line represents mean monthly semi-natural food availability. This was based on a study on five groups of urban vervet monkeys at Simbithi eco-estate, KwaZulu-Natal, South Africa 
Table 3 Results of GLMM model of factors influencing the foraging behaviour of urban vervet monkeys, Simbithi ecoestate, KwaZulu-Natal, South Africa, March 2016 - February 2017. Model $R^{2}=0.69$

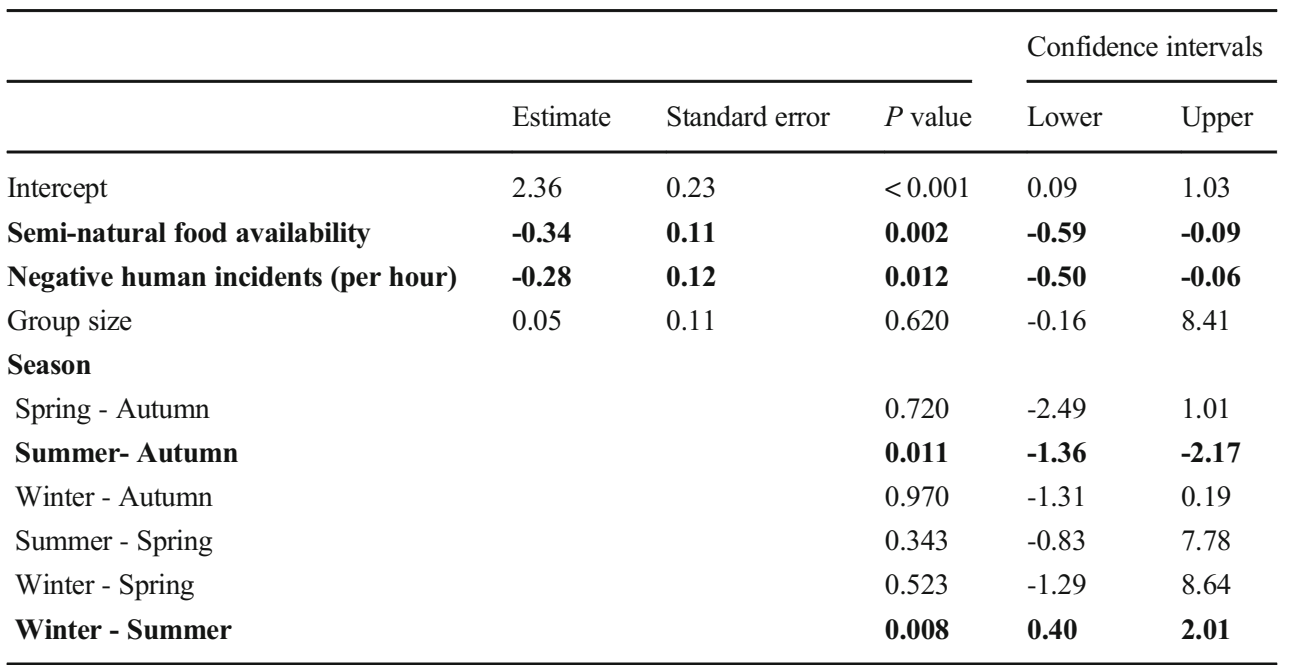

practicing efficient food storage. Furthermore, we suggest estate management should minimise anthropogenic-food consumption opportunities (e.g. vervet proof refuse bins and skips), which has previously been shown to be a successful management plan (e.g. Strum 2010).

Our statistical analysis showed that increased semi-natural food availability had a significant negative effect on the percentage of time spent foraging on human food, implying that foraging on anthropogenic food increases when the availability of semi-natural food decreases because of the lack of alternative feeding sources. Therefore, increasing semi-natural food availability could be used as a management strategy to decrease the percentage of time vervet monkeys feed on anthropogenic food and increase time spent foraging on semi-natural food. However, to implement increased vegetation as a successful management strategy, more research is required on specific phenological foraging patterns to target preferred plant species. Additionally, encouraging vervet monkeys' consumption of semi-natural food in the ecoestate could increase conflict with humans because of the aesthetic value horticultural plants to residents. A further management strategy could be to create supplementary foraging patches, providing preferred food items away from human residences. However, supplementary food patches are known to increase aggression and are likely to be dominated by higher ranked individuals leading to rank dependent
Fig. 2 (a) shows the negative effect of semi-natural food availability on the percentage of time spent foraging and (b) shows the negative effect of negative human incidents per hour on the percentage of time spent foraging for five groups of urban vervet monkeys at Simbithi eco-estate, KwaZuluNatal, South Africa (a)

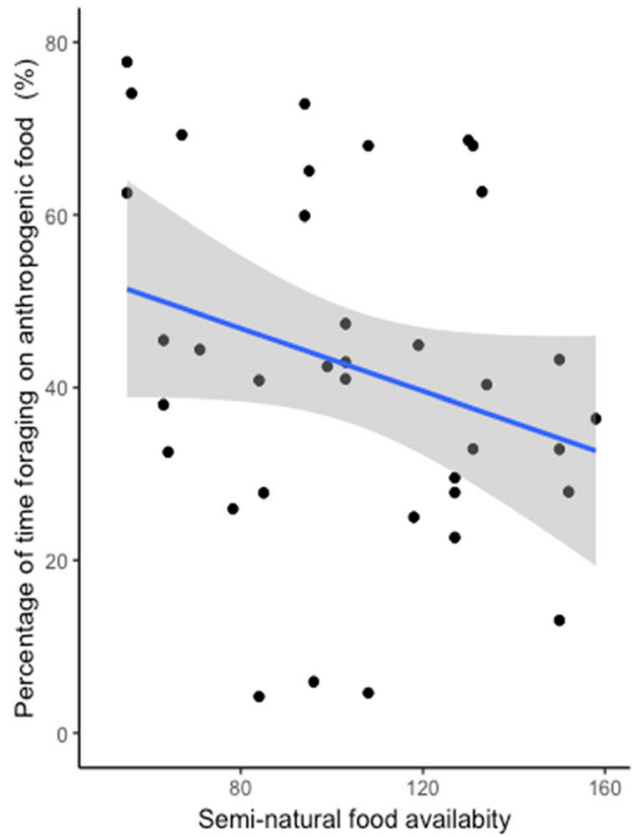

(b)

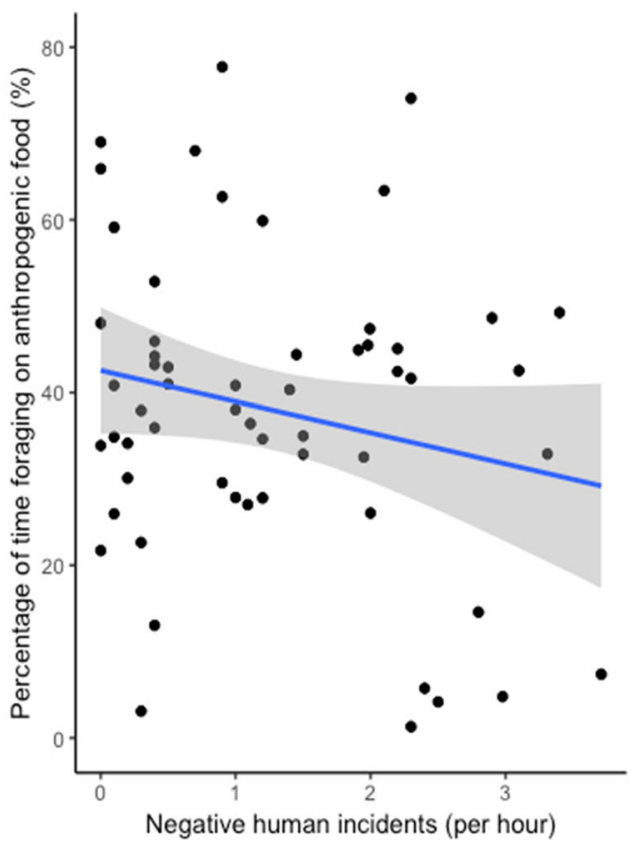


reproductive costs (King et al. 2008; Strum 2010; Kaplan et al. 2011), as well as increasing proximity and likelihood of disease transmission (Klaus et al. 2018). Thus, if supplementary foraging patches are implemented effort should be made to disperse such foraging patches as much as possible to reduce intragroup competition.

Additionally, we found that foraging rate was affected by seasonality, with increased foraging on anthropogenic food in winter and autumn when semi-natural food availability was lowest. Seasonal findings support previous research on primates living in the anthropogenic landscape, suggesting seasonal foraging fluctuations in the anthropogenic environment may be an adaptive foraging behaviour (van Doorn et al. 2010; Jaman and Huffman 2013; Thatcher et al. 2019b). We can consider these seasonal fluctuations to make more implicit management recommendations. Our data showed that foraging on anthropogenic food was highest in the winter months when semi-natural food availability was low, supporting dated research on vervet monkeys at tourist lodges (Brennan et al. 1985) and urban wildlife research (Widdows and Downs 2015). We suggest that management could therefore focus preventative methods to reduce anthropogenic food foraging opportunities in winter months and make residents aware of the increased likelihood of vervet monkey presence at anticipated sources of anthropogenic food. Furthermore, management could consider increasing vegetation which is mature and fruitful during winter months. Descriptive data showed that fruits and grasses were the predominant semi-natural food consumed by vervet monkeys, therefore, increasing the abundance of these resources in winter months within the estate could minimise negative human interactions.

Our findings for negative human incidents showed that increased human aggression decreased the percentage of time spent foraging on anthropogenic food. This finding supports previous research, which has shown that human food and human aggression can have interacting effects on vervet monkeys foraging time budget (Thatcher et al. 2019b), highlighting a need to consider multiple facets of human-wildlife interactions within anthropogenic studies. Our results also suggest that vervet monkey groups that receive more aggression from humans may spend more time being vigilant whilst feeding and therefore human-aggression acts as a time constraint, supporting recent studies on urban macaques (Kaburu et al. 2019a, b; Marty et al. 2019a). Although our negative human incidents results imply that increased aggression towards vervet monkeys will reduce foraging, the use of aggression as a management plan should be avoided because of welfare concerns. In the effort to improve human-primate cohabitation, research and management are collaboratively taking a step towards identifying prevention and reduction strategies rather than promoting direct aggression which may encourage an antagonistic human-wildlife relationship. Additionally, prior research has highlighted the complex relationship between costs and benefits of urban foraging in vervet monkeys, indicating that if vervet monkeys have access to high value anthropogenic food, then despite human-aggression, their time spent foraging would increase (Thatcher et al. 2019b).

As human populations increase, an enhanced understanding of urban wildlife ecology and consistent terminology is critical. As has been acknowledged throughout this paper, the definition of natural food for wildlife living in the anthropogenic landscape needs consideration, and we suggest moving forward "semi-natural food" should be used within urban ecology to refer to managed vegetation. Additionally, refined terminology will allow for easier cross comparisons between studies. Researchers should be mindful of our definition of semi-natural food when applying the results to other anthropogenic studies. Finally, it should be acknowledged that the measure of semi-natural food used in this study was a retrospective measure and therefore not a precise representation of vegetation available during behavioural observations. Proper phenological assessments, such as that recommended by Marshall and Wich (2013), should be considered before implementing the findings of this study for management.

\section{Conclusions}

Our data can be used to suggest multiple management strategies, focusing on seasonal trends in food availability, both anthropogenic and semi-natural. It should be noted that before implementing any management strategies that may alter foraging patterns of wildlife, further research is needed on potential fitness costs that may have further consequences for the human-wildlife relationship, such as disease transmission or reduced nutrient availability.

Data provided clearly highlight vervet monkeys apply a flexible foraging strategy to increase calorific intake and reduce associated negative costs of human-wildlife cohabitation in the urban landscape. Our research is complimentary to that on other urban wildlife, emphasising the importance of foraging flexibility to the success of urban wildlife (Lowry et al. 2013; Widdows and Downs 2018; Stofberg et al. 2019). We provide a foundation for future research into urban wildlife foraging patterns that will hopefully help towards managing the human-wildlife interface in the urban ecosystem.

Acknowledgements We would like to thank Simbithi Eco-estate for allowing us to conduct our research within their estate and supporting this project. We would also like to thank Liverpool John Moores University (UK), the University of KwaZulu-Natal (ZA) and the National Research Foundation (ZA) for their support during this period. This work was supported by an Erasmus Mundus AESOP (A European and South African Partnership on Heritage and Past) grant (ES15DM0025) to HT. 
Open Access This article is licensed under a Creative Commons Attribution 4.0 International License, which permits use, sharing, adaptation, distribution and reproduction in any medium or format, as long as you give appropriate credit to the original author(s) and the source, provide a link to the Creative Commons licence, and indicate if changes were made. The images or other third party material in this article are included in the article's Creative Commons licence, unless indicated otherwise in a credit line to the material. If material is not included in the article's Creative Commons licence and your intended use is not permitted by statutory regulation or exceeds the permitted use, you will need to obtain permission directly from the copyright holder. To view a copy of this licence, visit http://creativecommons.org/licenses/by/4.0/.

\section{References}

Altmann J (1974) Observational study of behavior: sampling methods. Behaviour 49:227-266

Baker PJ, Harris S (2007) Urban mammals: what does the future hold? An analysis of the factors affecting patterns of use of residential gardens in Great Britain. Mammal Rev 37:297-315

Bateman PW, Fleming PA (2012) Big city life: Carnivores in urban environments. J Zool 287:1-23. https://doi.org/10.1111/j.14697998.2011.00887.x

Bates DM (2010) lme4: Mixed-effects modeling with R. Springer, New York

Becker DJ, Hall RJ (2014) Too much of a good thing: resource provisioning alters infectious disease dynamics in wildlife. Biol Lett 10: 20140309

Blake JG (1990) Quantifying abundance of fruits for birds in tropical habitats. Cuantificación de la abundancia de frutos para aves en hábitats tropicales. Stud Avian Biol 13:73-79

Boon R (2010) Pooley's Trees of Easten South Africa, 2nd edn. Natal Flora Publcations Trust, KwaZulu-Natal

Bradley CA, Altizer S (2007) Urbanization and the ecology of wildlife diseases. Trends Ecol Evol 22:95-102

Brennan EJ, Else JG, Altmann J (1985) Ecology and behaviour of a pest primate: vervet monkeys in a tourist-lodge habitat. Afr J Ecol 23:3544

Bryson-Morrison N, Matsuzawa T, Humle T (2016) Chimpanzees in an anthropogenic landscape: examining food resources across habitat types at Bossou, Guinea, West Africa. Am J Primatol 78:1237-1249

Bryson-Morrison N, Tzanopoulos J, Matsuzawa T, Humle T (2017) Activity and habitat use of chimpanzees (Pan troglodytes verus) in the anthropogenic landscape of Bossou, Guinea, West Africa. Int J Primatol 38:282-302

Cancelliere EC, Chapman CA, Twinomugisha D, Rothman JM (2018) The nutritional value of feeding on crops: Diets of vervet monkeys in a humanized landscape. Afr J Ecol 56:160-167

Chapman CA, Chapman LJ, Zanne AE et al (2005) A 12-year phenological record of fruiting: implications for frugivore populations and indicators of climate change. In: Dew JL, Boubli JP (eds) Tropical fruits and frugivores. Springer, pp 75-92

Chaves ÓM, Bicca-Marques JC (2016) Feeding strategies of brown howler monkeys in response to variations in food availability. PLoS One 11:e0145819

Freitas CH de, Setz EZF, Araújo ARB, Gobbi N (2008) Agricultural crops in the diet of bearded capuchin monkeys, Cebus libidinosus Spix (Primates: Cebidae), in forest fragments in southeast Brazil. Rev Bras Zool 25:32-39

Dickman AJ (2010) Complexities of conflict: the importance of considering social factors for effectively resolving human-wildlife conflict. Anim Conserv 13:458-466

Fox J, Friendly GG, Graves S et al (2007) The car package. R Found Stat Comput
Ghasemi A, Zahediasl S (2012) Normality tests for statistical analysis: a guide for non-statisticians. Int J Endocrinol Metab 10:486-489

Hockings KJ, Anderson JR, Matsuzawa T (2009) Use of wild and cultivated foods by chimpanzees at Bossou, Republic of Guinea: feeding dynamics in a human-influenced environment. Am J Primatol 71: 636-646

Hockings KJ, McLennan MR, Carvalho S et al (2015) Apes in the Anthropocene: Flexibility and survival. Trends Ecol Evol 30:215222

Hoffman TS, O'Riain MJ (2012) Landscape requirements of a primate population in a human-dominated environment. Front Zool 9:1-17

Humle T, Hill C (2016) People-primate interactions: implications for primate conservation. In: Wich SA, Marshall AJ (eds) Introduction to Primate Conservation. Oxford University Press, Oxford, pp 219 240

Jaman MF, Huffman MA (2013) The effect of urban and rural habitats and resource type on activity budgets of commensal rhesus macaques (Macaca mulatta) in Bangladesh. Primates 54:49-59

Jokimäki J, Kaisanlahti-jokimäki M, Suhonen J et al (2011) Merging wildlife community ecology with animal behavioral ecology for a better urban landscape planning. Landsc Urban Plan 100:383-385

Kaburu SSK, Beisner B, Balasubramaniam KN et al (2019a) Interactions with humans impose time constraints on urban-dwelling rhesus macaques (Macaca mulatta). Behaviour 156:1-28

Kaburu SSK, Marty PR, Beisner B et al (2019b) Rates of humanmacaque interactions affect grooming behavior among urbandwelling rhesus macaques (Macaca mulatta). Am J Phys Anthr 168:92-103

Kaplan BS, O'Riain MJ, van Eeden R, King AJ (2011) A low-cost manipulation of food resources reduces spatial overlap between baboons (Papio ursinus) and humans in conflict. Int J Primatol 32: 1397-1412

King AJ, Douglas CMS, Huchard E et al (2008) Dominance and affiliation mediate despotism in a social primate. Curr Biol 18:1833-1838

Klaus A, Strube C, Röper KM et al (2018) Fecal parasite risk in the endangered proboscis monkey is higher in an anthropogenically managed forest environment compared to a riparian rain forest in Sabah, Borneo. PLoS One 13:e195584

Lambert JE (2005) Competition, predation, and the evolutionary significance of the cercopithecine cheek pouch: the case of Cercopithecus and Lophocebus. Am J Phys Anthropol 126:183-192

Litvaitis JA (2000) Investigating food habits of terrestrial vertebrates. Res Tech Anim Ecol Controv consequences 165-190

Lowry H, Lill A, Wong B (2013) Behavioural responses of wildlife to urban environments. Biol Rev 88:537-549

Marshall AJ, Wich S (2013) Characterization of primate environments through assessment of plant phenology. In: Sterling E, Blair M, Bynum N (eds) Primate ecology and conservation: A handbook of techniques. Oxford University Press, Oxford

Marty P, Beisner B, Kaburu SSK et al (2019a) Time constraints and stress imposed by human presence alter social behaviour in urban longtailed macaques. Anim Behav 168:92-103

Marty PR, Balasubramaniam KN, Kaburu SSK et al (2019b) Individuals in urban dwelling primate species face unequal benefits associated with living in an anthropogenic environment. Primates 61:249-255

McKinney ML (2002) Urbanization, biodiversity, and conservation: the impacts of urbanization on native species are poorly studied, but educating a highly urbanized human population about these impacts can greatly improve species conservation in all ecosystems. Bioscience 52:883-890

McLennan MR, Ganzhorn JU (2017) Nutritional characteristics of wild and cultivated foods for chimpanzees (Pan troglodytes) in agricultural landscapes. Int J Primatol 38:122-150

McLennan MR, Spagnoletti N, Hockings KJ (2017) The Implications of Primate Behavioral Flexibility for Sustainable Human-Primate Coexistence in Anthropogenic Habitats. Int J Primatol 38:105-121 
Ménard N, Motsch P, Delahaye A et al (2013) Effect of habitat quality on the ecological behaviour of a temperate-living primate: Time-budget adjustments. Primates 54:217-228

Nowak K, Lee PC (2013) Specialist primates can be flexible in response to habitat alteration. In: Primates in Fragments: Complexity and Resilience, In Primate. Springer, New York, pp 199-211

Nyhus PJ (2016) Human-wildlife conflict and coexistence. Annu Rev Environ Resour 41:143-171

Oro D, Genovart M, Tavecchia G, Fowler MS, Martínez-Abraín A (2013) Ecological and evolutionary implications of food subsidies from humans. Ecol Lett 16(12)1501-1514

Patterson L, Kalle R, Downs C (2017) A citizen science survey: perceptions and attitudes of urban residents towards vervet monkeys. Urban Ecosyst 20:617-628

Patterson L, Kalle R, Downs CT (2019) Living in the suburbs: Space use by vervet monkeys (Chlorocebus pygerythrus) in an eco-estate, South Africa. Afr J Ecol 57:539-551

Pautasso M, Böhning-Gaese K, Clergeau P et al (2011) Global macroecology of bird assemblages in urbanized and semi-natural ecosystems. Glob Ecol Biogeogr 20:426-436

$\mathrm{R}$ project (2013) R: A language and environment for statistical computing. R Foundation for Statistical Computing: Vienna, Austria. http:// www.r-project.org/. Accessed 21 Sep 2019

Saj T, Sicotte P, Paterson JD (1999) Influence of human food consumption on the time budget of vervets. Int J Primatol 20:974-977

Sha JCM, Hanya G (2013) Diet, activity, habitat use, and ranging of two neighboring groups of food-enhanced long-tailed macaques (Macaca fascicularis). Am J Primatol 75:581-592

Sol D, Timmermans S, Lefebvre L (2002) Behavioural flexibility and invasion success in birds. Anim Behav 63:495-502

Soulsbury CD, White PCL (2015) Human-wildlife interactions in urban areas: A review of conflicts, benefits and opportunities. Wildl Res 42:541-553

Stofberg M, Cunningham SJ, Sumasgutner P, Amar A (2019) Juggling a "junk-food" diet: responses of an urban bird to fluctuating anthropogenic-food availability. Urban Ecosyst 22:1019-1026

Strum SC (2010) The development of primate raiding: implications for management and conservation. Int J Primatol 31:133-156

Thabethe V, Downs CT (2018) Citizen science reveals widespread supplementary feeding of African woolly-necked storks in suburban areas of KwaZulu-Natal, South Africa. Urban Ecosyst 21:965-973
Thatcher HR (2019) Anthropogenic influences on the behavioural ecology of urban vervet monkeys. Liverpool John Moores University

Thatcher HR, Downs CTCT, Koyama NFNF (2018) Using parasitic load to measure the effect of anthropogenic disturbance on vervet Monkeys. Ecohealth 15:676-681

Thatcher HR, Downs CT, Koyama NF (2019a) Positive and Negative Interactions with Humans Concurrently Affect Vervet Monkey (Chlorocebus pygerythrus) Ranging Behavior. Int J Primatol 40: 496-510

Thatcher HR, Downs CTCT, Koyama NFNF (2019b) Anthropogenic influences on the time budgets of urban vervet monkeys. Landsc Urban Plan 181:38-44

Tilman D, Clark M, Williams DR et al (2017) Future threats to biodiversity and pathways to their prevention. Nature 546:73-81

Trueman IC (2017) Issues in urban nature conservation (plants and vegetation). In: Rotherham ID (ed) Urban environments-history, biodiversity \&culture. Wildtrack Publishing

van Doorn AC, O'Riain MJ, Swedell L (2010) The effects of extreme seasonality of climate and day length on the activity budget and diet of semi-commensal chacma baboons (Papio ursinus) in the Cape Peninsula of South Africa. Am J Primatol 72:104-112

Widdows CD, Downs CT (2015) A genet drive-through: are large spotted genets using urban areas for "fast food"? a dietary analysis. Urban Ecosyst 18:907-920

Widdows CD, Downs CT (2016) Urban roost temperatures of large-spotted-genets: The effect of anthropogenic structures. J Therm Biol 57: 66-71

Widdows C, Downs CT (2018) Genets in the city: community observations and perceptions of large-spotted genets (Genetta tigrina) in an urban environment. Urban Ecosyst 21:357-367

Wirminghaus JO, Downs CT, Symes CT, Perrin MR (2001) Fruiting in two afromontane forests in KwaZulu-Natal, South Africa: the habitat type of the endangered Cape Parrot Poicephalus robustus. South African J Bot 67:325-332

Wood M (2005) Bootstrapped confidence intervals as an approach to statistical inference. Organ Res Methods 8:454-470

Woodroffe R, Thirgood S, Rabinowitz A (2005) People and wildlife, conflict or co-existence? Cambridge University Press, Cambridge

Zuur AF, Ieno EN, Elphick CS (2010) A protocol for data exploration to avoid common statistical problems. Methods Ecol Evol 1:3-14 